Int. J. Dev. Biol. 49: 325-333 (2005)

doi: $10.1387 / \mathrm{ijdb} .041932 \mathrm{ha}$

\title{
Three developmental compartments involved in rib formation
}

\author{
HIROHIKO AOYAMA*,1, YOKO MIZUTANI-KOSEKI ${ }^{2}$ and HARUHIKO KOSEKI ${ }^{2,3}$ \\ ${ }^{1}$ Department of Anatomy and Developmental Biology, Graduate School of Medical Sciences, Hiroshima University, Minami-ku, Hiroshima, \\ Japan, ${ }^{2}$ Department of Molecular Embryology, Graduate School of Medicine, Chiba University, Chuoh-ku, Chiba, Japan and ${ }^{3}$ RIKEN \\ Research Center for Allergy and Immunology, Yokohama, Japan
}

\begin{abstract}
When the thoracic somitic mesoderm was separated from the neural tube and the notochord with a piece of aluminum foil in two-day chick embryos, seven days after the operation ribs lacked their proximal part. The embryos were rescued by co-transplanting the notochord, the ventral half of neural tube, or QT6 cells transformed with Shh, on the somite side of the aluminum foil insert. Thus, proximal rib development depends on the notochord and the ventral neural tube, an effect which might be mediated through Shh secreted by these axial tissues. On the other hand, when the thoracic somitic mesoderm was separated from the surface ectoderm by a piece of polyethylene terephthalate film, the distal parts of the ribs were missing, suggesting that distal rib development depends on surface ectoderm. In these embryos, expression of Pax 3 was weak and perturbed showing that the dermomyotome developed abnormally. It is not clear whether the development of distal rib is mediated by the dermomyotome, or the ectoderm. It has previously been shown that sternal rib development depends on lateral plate mesoderm. As to the distal rib, it is considered to be composed of two parts. Thus, the rib is composed of three developmental compartments, in agreement with a recently presented classification of somite derivatives as primaxial and abaxial.
\end{abstract}

KEY WORDS: proximal rib, distal rib, somitic mesoderm, Shh, surface ectoderm

\section{Introduction}

\section{From the neural crest to the somite}

One of the authors (H. A.), working for two years as a post-doc in Nogent, studied the role of cell adhesion in neural crest cellderived gangliogenesis (Aoyama et al., 1985). Back in Japan, he decided not only to continue studying the neural crest but also began studying the morphogenesis of the axial skeleton from the somite. Several years later, he found that quite a few investigators in Nogent also began studying somite development. Considering the respective properties of the neural crest and the somites, it is natural that somite development deeply interests researchers studying the neural crest. First, both types of structures develop as segmental units. The ganglia of peripheral nervous system derive from the neural crest, while the axial skeleton and the trunk and limb muscles derive from the somites. Since segmentation of neural crest is caused by the interaction between the neural crest and the somites (Rickmann et al., 1985; Goldstein et al., 1990), the segmentation of somites must play a fundamental role. Secondly, the cells from both tissues migrate from their early commitment sites to their final position where they differentiate to form the structures they are fated to. Thirdly and most important, their developmental repertoire varies along the rostro-caudal axis. Cranial crest can differentiate into cartilage, while trunk crest cannot. Somites form region-specific units of the axial skeleton. For example, in the axial skeleton of birds and mammals, ribs are found exclusively in the thoracic region.

\section{Rib formation}

Recent findings in developmental biology throw new light on mechanisms of evolution (Carroll et al., 2001). Concerning the phylogeny of vertebrates, the axial skeleton has been one of the major subjects of study (Burke et al., 1995). The rib is a simple and essential model for studying both regional specification in developing vertebrates and animal diversity. Rib diversity along the vertebrate body axis is not only a developmental feature but also a phylogenic one and is under the control of Hox genes (Burke et al., 1995). Although the rib is restricted to the thoracic region of birds and mammals, it is supposed to contribute to some vertebrae as, for example, the costal process in the lumbar vertebrae (Standring, 2005).

Ribs as well as vertebrae have been shown to derive from the somites (Seno, 1961; Pinot, 1969; Christ et al., 1974; Chevallier, 1975; reviewed by Christ and Wilting, 1992; Tam and Trainor,

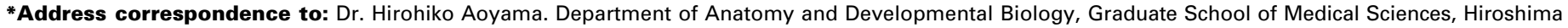
University, 1-2-3 Kasumi, Minami-ku, Hiroshima 734-8551, Japan. Fax: +81-82-257-5114. e-mail: aoyamah@hiroshima-u.ac.jp
} 
1994; Christ et al., 1998). Region specific morphogenesis of the axial skeleton can be divided into two phases. In the first phase somitic mesoderm becomes regionalized. Kieny et al. (1972) first showed by heterotopic transplantations that the somites and segmental plate of chick embryos were already regionalized. Whether they form ribs or not depends on their original position along the rostro-caudal axis of the embryo, a finding confirmed by Chevallier (1975) with the chick-quail chimera system. If thoracic somites or segmental plate were transplanted into the cervical region they formed ribs and, if cervical somitic mesoderm was transplanted into thoracic region, it did not form ribs. Our recent data suggest such regionalization occurs in the presumptive somitic mesoderm as early as the primitive streak stage (Sakamoto and Aoyama, in preparation).

The second phase is the sequential process of somite cell differentiation and morphogenesis that constructs skeleton morphology. When the somite becomes segmented from the segmental plate, it is composed of an epithelial sac enclosing mesenchymal somitocoel cells. Thereafter the somite differentiates into two parts, the ventro-medial mesenchymal sclerotome and the dorso-lateral epithelial dermomyotome. This change in the epithelial somite depends on surrounding tissue (for example, Gallera, 1966; Swalla and Solursh, 1984; Aoyama \& Asamoto, 1988; Christ et al., 1992; Aoyama, 1993; Dietrich etal., 1997; also reviewed by Dockter, 2000; Christ et al., 2004) and becomes initiated within three hours (Aoyama \& Asamoto, 1988), although the sclerotomal cells once differentiated can still change their developmental fate (Dockter and Ordahl, 2000). Sclerotome differentiation depends on the axial tissues such as the notochord and the floor plate and on Shh produced by these tissues (Watterson et al., 1954; Teillet and Le Douarin, 1983; Brand-Saberi et al., 1993; Fan and Tessier-Lavigne, 1994; Johnson et al., 1994; Fan et al., 1995; Chiang et al., 1996; Borycki et al., 1997; Dietrich et al., 1997). On the other hand dermomyotome differentiation depends on the surface ectoderm (Gallera, 1966; Dietrich et al., 1997). Furthermore, the myotome appears at the medial and the lateral edges of the dermomyotome. The former gives rise to epaxial muscles and the latter to hypaxial muscles. Epaxial muscles development is considered to depend on the notochord and neural tube and hypaxial muscles on lateral plate mesoderm and surface ectoderm (reviewed by Christ and Ordahl, 1995; Dietrich, 1999; Borycki and Emerson, 2000). Thus, tissues surrounding the somite regulate the specification of somite into compartments.

Inthe presentstudy, we examined the role of the tissues surrounding the somite in rib formation. When the interaction between the somite and the axial tissues was interrupted by inserting a piece of nonpermeable film between the tissues in 2-day chick embryos, the proximal rib did not develop, while the interruption between the surface ectoderm and the somite caused loss of the distal rib. We previously showed that the lateral plate was essential for the development of sternal ribs, more specifically of the distal part of the distal rib in avian embryos (Sudo et al., 2001). Here we report that the three parts of the rib, proximal, distal and sternal, are developmentally different compartments. We will discuss these compartments, in relation to a new classification of somite derivatives, primaxial and abaxial (Burke and Nowicki, 2003).

\section{Results}

\section{Rrole of medial tissues in the development of the proximal rib}

\section{Block of somite-axial tissue interaction}

A piece of aluminum foil of about $1 / 4-1 / 3 \mathrm{~mm}$ by $1 \mathrm{~mm}$ was inserted between the thoracic somitic mesoderm along 6 somites and the neural tube and notochord in a 2-day chick embryo (Fig.1A, B). The somitic mesoderm concerned was at different levels, i.e., at different
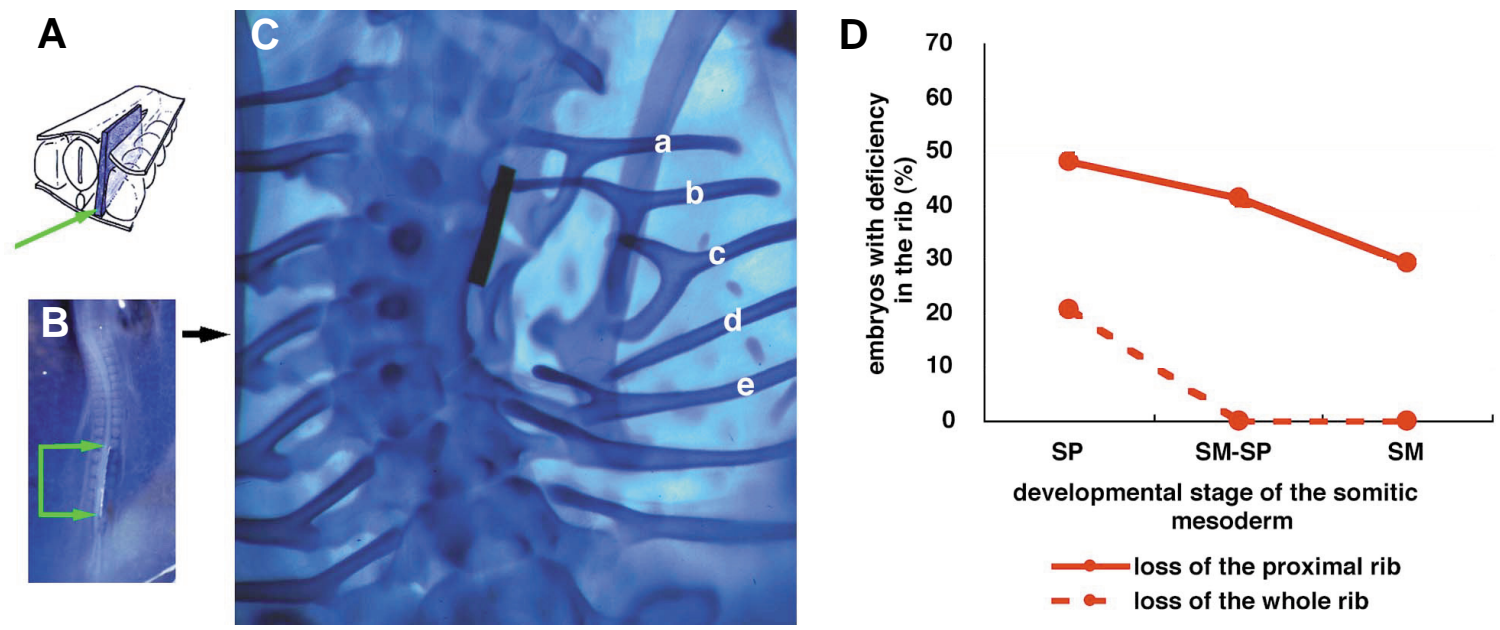

Fig. 1. Deficiency in the rib caused by blocking the interaction between the thoracic somitic mesoderm and the axial tissues in 2-day chick embryos. (A) Schematic drawing of the operation. A piece of aluminum foil (ca. 1/4-1/3 mm $\times 1 \mathrm{~mm}$; blue rectangle, indicated with green arrow) was inserted between the axial tissues (the neural tube and the notochord) and the somitic mesoderm. (B) Dorsal view of the embryo immediatly after the operation. Position of the aluminum foil insert is indicated with green arrows. (C) Whole mount Alcian blue staining showing the cartilaginous skeleton 7 days after the operation. Ribs display various degrees of malformation in their proximal part (a-e; detail in text). In the most severe cases, the proximal rib (head, neck and tuberculum of rib) is completely lost (d). (D) Incidence of embryos with rib deficiency depends on the developmental stage of the somitic mesoderm at the operation, i.e., unsegmented segmental plate (SP), somitic mesoderm including both segmented somites and unsegmented segmental plate (SM-SP) or already segmented somites (SM). The earlier the developmental stage of somitic mesoderm operated, the more frequently the proximal rib is missing (red solid line). Only when the barrier was inserted between the segmental plate and the axial tissues, was the whole rib missing (red broken line). 
stages of somite development. The foil piece was inserted at the level of either unsegmented thoracic somitic mesoderm (segmental plate, SP), either both somites and segmental plate (SM-SP), or already segmented somites (SM). Seven days after the operation, the proximal ribs displayed various malformations. Fig.1C shows a typical embryo with various malformations of proximal ribs. Compared to a more or less normal rib (a), the tuberculum (b), the head (e) or both were separated from the vertebral column and in more severe cases the proximal rib was completely missing (d). Such malformations are not caused by the toxicity of aluminum, because, in seven cases, insertion of smaller pieces of aluminum (0.2-0.3 mm square) did not affect formation (data not shown).

The appearance of a deficiency in the proximal rib was found to depend on the developmental stage of the somitic mesoderm when separated from the neural tube and notochord (Fig.1D). 14 out 29 embryos (48\%) in the case of non-segmented thoracic somitic mesoderm (stage SP in Fig.1D abscissa), 12/29 (41\%) in the case of both segmental plate and somites (stage SM-SP in Fig.1D abscissa), $17 / 5(29 \%)$ in the case of already segmented somites (stage SM in Fig.1D abscissa), respectively (Fig.1D, solid line).

When the piece of foil was inserted between the thoracic segmental plate and the axial tissues, a whole rib was often lost ( 6 out 29 embryos $=21 \%$ ) (Fig.1D, dotted line). The whole rib was never lost in the case of operations at the SM-SP $(n=29)$ or SM stages $(n=17)$.

\section{Pax1 expression pattern}

Koseki etal.(1993) showed that Pax1 mediates of the notochordal signal which controls the ventral vertebra and the proximal rib. To know whether the block of the axial tissue affects Pax 1expression as well as proximal rib development, the expression pattern in operated embryos was examined by whole mount in situ hybridization using a digoxigenin labeled riboprobe for quail Pax1 cDNA.

Two days after the operation, the expression of Pax1 in the somites was down regulated at the site where the aluminum foil was inserted (Fig.2A, B; between two green arrows) compared to those on the opposite non-operated side. Elsewhere, Pax1 was expressed equally on the operated and on the non-operated side.

\section{Back-transplantation of axial tissues}

Finding that blocking the interaction between the somite and the axial tissues caused a malformation in the proximal rib suggests that proximal rib development depends on the neural tube and/or the notochord. However, it is not clear which tissue is required to form the proximal rib. To clarify this issue, after inserting a piece of aluminum foil between the axial tissues and the somitic mesoderm, we inserted either the dorsal half of neural tube, the ventral half of neural tube, or the notochord from quail embryos between the foil and the somitic mesoderm (Fig.3A).

Seven days after back-transplantation of the notochord, the ventral neural tube or the dorsal neural tube at stage SP, the ratio of embryos missing proximal ribs to the total number of the operated embryos were 4/13 (31\%), 4/10 (40\%) and 9/16 (56\%), respectively (Fig.3B). They were 2/18 (11\%), 1/15 (7\%) and 13/20 (65\%), respectively, in cases operated at stage SM-SP and 0/6 (0\%), 0/9 $(0 \%)$ and $2 / 5(40 \%)$, respectively, in cases operated at stage SM. When the aluminum foil was inserted without any tissues, the ratio of embryos missing proximal ribs were 12/29 (41\%), 5/17 (29\%) and 14/ $29(48 \%)$ as stated above. Thus the incidence of the deficiency in the proximal rib was lower in embryos with back transplanted notochord
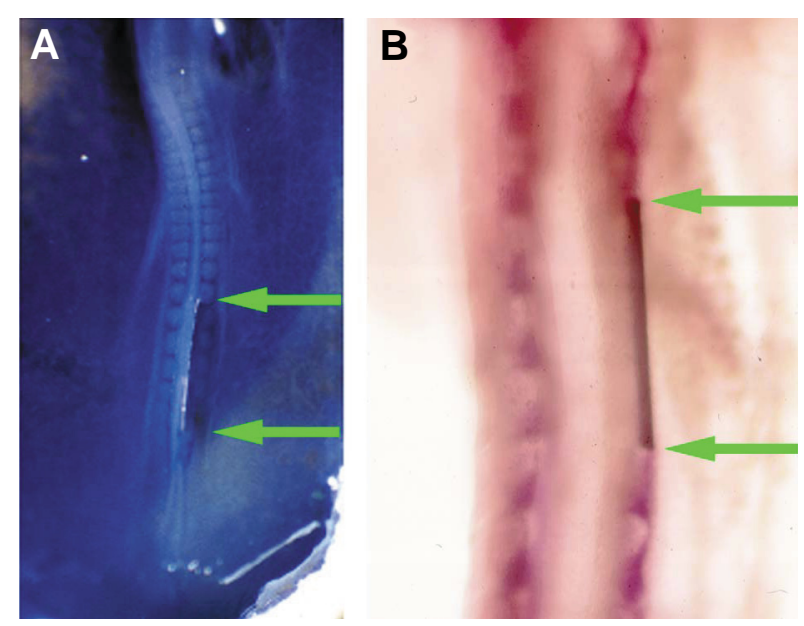

Fig. 2. Pax1 expression pattern in embryos when interaction between the somitic mesoderm and the axial tissues is blocked. (A) Dorsal view of 2-day chick embryo immediatly after the operation. Position of the aluminum insert is indicated with two green arrows. (B) Whole mount in situ hybridization using Pax1 probe performed of the embryo 2 days after the operation. Dorsal view. Upper is rostral. Pax1 expression is not found in the somites that are separated from the axial tissues with the aluminum barrier (between two green arrows), while a periodical Pax 1 expression pattern was seen on the opposite, non-operated side. Rostral to and caudal to the operated site, Pax1 was expressed on both sides concordantly.

or ventral neural tube and was slightly higher in the embryos with dorsal neural tube transplants than in the embryos without backtransplantation.

Thus, back-transplantation of the notochord or the ventral neural tube rescued the embryo from the deficiency in the proximal ribs, while the dorsal neural tube did not. Rather, the dorsal neural tube appeared to promote the deficiency. These findings suggest that the notochord and/or the ventral neural tube are responsible for proximal rib formation.

\section{Co-transplantation of Shh-producing cells}

It is well known that the notochord and the floor plate, that is, the ventral most part of the neural tube, induce motor neurons (Yamada et al., 1991; Roelink et al., 1995) and sclerotomal differentiation (Fan and Tessier-Lavigne, 1994; Johnson etal., 1994; Fan etal., 1995) by producing and secreting Shh. To know whether the dependence of the proximal rib development on the notochord and/or the ventral neural tube is also mediated by Shh, we examined the effect of transplanting Shh-producing cells. After inserting a piece of aluminum foil between the axial tissues and the thoracic somitic mesoderm at SM-SP stage, QT6 cells transformed with Shh gene were transplanted between the foil and the somitic mesoderm (Fig.4A). As control, we used the original QT6 cells instead of their transformants (Fig.4B).

Seven days after the operation with the transplantation of Shhproducing QT6 cells or of the original QT6 cells, the ratio of embryos missing proximal ribs were $3 / 18(17 \%)$ and $8 / 12(67 \%)$, respectively. The incidence of the proximal rib deficiency was thus much lower in the embryos inserted with barrier and Shh-producing cells than in those inserted with barrier and Shh-non-producing cells.

Thus the Shh producing QT6 cells rescued embryos in which the interaction between the axial tissues and the thoracic somitic mesoderm was blocked, so that proximal ribs were normal (Fig.4C), 

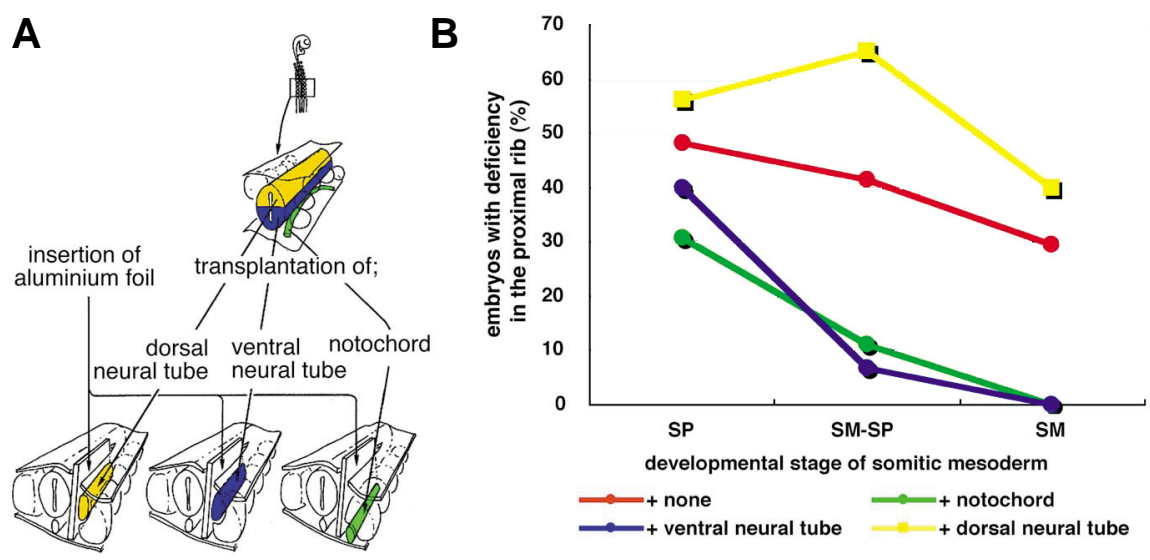

Fig. 3. Back-transplantation experiments showing the part of axial tissues responsible for proximal rib morphogenesis. (A) Schematic drawing of the experiment. Insertion of a piece of aluminum foil between the somitic mesoderm and the axial tissues of 2 day chick embryos was followed by transplantation of the dorsal half of neural tube, the ventral half of neural tube, or the notochord from quail embryos, between the aluminum insert and the somitic mesoderm. (B) Incidence of embryos with a deficiency in the proximal rib 7 days after the operation. Compared to the control embryo with only an aluminum insert (red line), the notochord (green line) and ventral half of neural tube (blue line) have rescued the embryos from the deficiency at least when they have been operated at SM-SP or SM stage, while the dorsal half of neural tube promoted the malformation (yellow line).

while normal QT6 cells did not (Fig.4D; arrow head indicates missing proximal rib)), suggesting that proximal rib development depends on the notochord and the ventral neural tube, and this effect might be mediated by Shh secreted by these axial tissues.

\section{Role of the surface ectoderm in development of the distal part of the rib}

We have reported that blocking the interaction between the somite and the somatopleure caused deficiency in the sternal rib (Sudo et al., 2001). However, the vertebral ribs were intact. That is, at least the proximal half of the distal rib development does not depend on the somatopleure. We therefore examined another tissue surrounding the somite, the surface ectoderm.

\section{Block of somite-ectoderm interaction}

Because aluminum foil is too thick to insert between surface ectoderm and somatic mesoderm, we used polyethylene terephthalate (PET) film as a barrier. A piece of PET film about $0.25-0.33 \mathrm{~mm}$ by $1 \mathrm{~mm}$ was inserted between the surface ectoderm and the thoracic somitic mesoderm at SM-SP stage in two-day chick embryos (Fig.5A; between green arrows). The width of the film was about twice the diameter of somite. Consequently, at the time of operation the PET insert was large enough to cover the somite. However, 24 hours after the operation, as the embryo grew, the width of the film became equal to the somite diameter. Besides, the film tended to move laterally. Therefore we checked the position of the film 24 hours after the operation to know whether the film covered the somite at least for the 24 hours.

Seven days after the operation, the distal ribs were found to be deficient (Fig.5B; red arrowheads) in all the embryos keeping the PET insert between the ectoderm and the somitic mesoderm for the first 24 hours $(n=13)$ (Table 1, case $1+$ case 2 + case 3$)$. Among these, in three embryos not only the somitic mesoderm but also part of the lateral plate mesoderm were covered (Table 1, case 2) and in seven cases the somite and part of the neural tube were covered (Table 1, case 3) with the insert for 24hours.

When the insert covered only part of the somite and lateral plate for the first 24 hours, the ratio of embryos lacking the distal ribs to total operated number were 6/ 21 (29\%) (Table 1, case 4), while covering only the lateral plate did not cause the loss of distal rib
Fig. 4. Co-transplantation experiment showing Shh can rescue the embryo from the proximal rib deficiency caused by a blocked interaction between the somitic mesoderm and the axial tissues. (A) Schematic drawing of the transverse section of a chick embryo operated at 2 days of incubation. Red dots indicate Shh distribution. After insertion of an aluminum foil barrier (blue bar) between the axial tissues and the somitic mesoderm, Shhproducing QT6 cells (OT6-Shh ; yellow bar with red dots) were transplanted between the aluminum insert and the somitic mesoderm. (B) Control operation. Instead of QT6-Shh cells, normal QT6 cells were transplanted. (C,D) Whole mount alcian blue staining of the embryos 7 days after the operation. Dorsal view. In the embryo with QT6-Shh cells, the ribs connected to the vertebral column and were considered to have the proximal rib (C), while the embryo with normal QT6 cells (D) showed a deficient proximal rib (red arrow head in D).
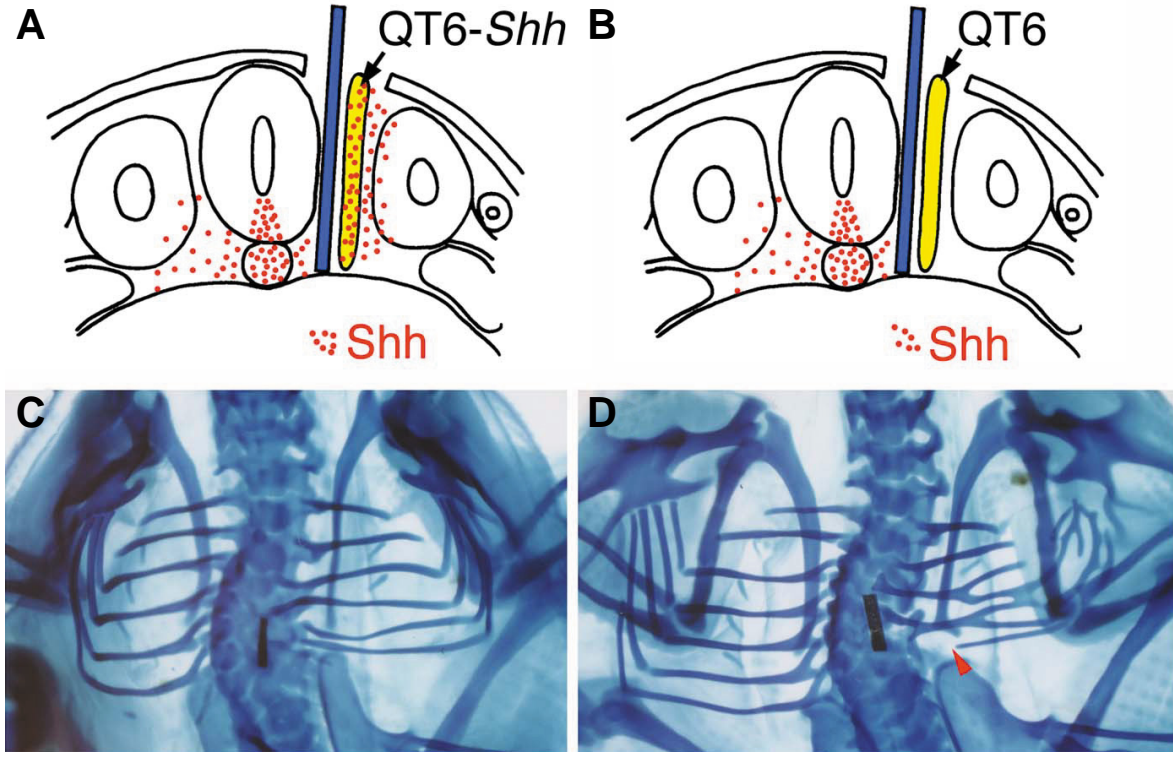

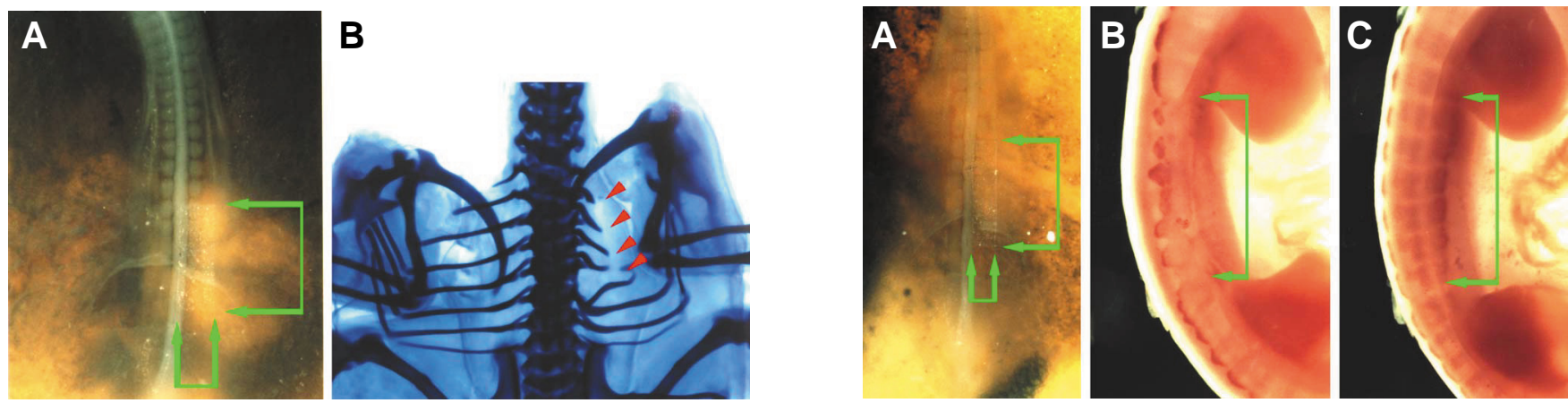

Fig. 5 (Left). Deficiency in the distal rib caused by blocking the interaction between the thoracic somitic mesoderm and the surface ectoderm in 2 day chick embryos. (A) Dorsal view of the embryo immediately after the operation. Upper is rostral. A piece of polyethylene terephthalate (PET) film (ca. 1/4-1/3 $\mathrm{mm} \times 1 \mathrm{~mm}$ ) was inserted underneath the surface ectoderm on the somitic mesoderm including both segmented somites and unsegmented segmental plate. PET film is indicated by two pairs of green arrows. (B) Dorsal view of the embryo 7 days after the operation. Whole mount alcian blue staining. On the operated site, only the proximal ribs were formed and the distal ribs were missing (red arrowheads).

Fig. 6 (Right). Pax3 expression pattern in the embryo with blocked interaction between thoracic somitic mesoderm and surface ectoderm. (A) Dorsal view of the embryo immediately after the operation. Details are in the legend for Fig. 5A. (B,C) Whole mount in situ hybridization using Pax3 probe performed 2 days after the operation. Lateral side view. Upper is rostral. On the operated side (B), Pax3 expression is down regulated, compared with that on the control side (C).

( $n=14)$ (Table 1, case 5), except for only the loss of the sternal rib in three cases, as has been reported previously (Sudo, et al., 2001). In the case when the insert covered both the somite and the neural tube partially, $21 \%(4 / 19)$ of the operated embryos lacked their distal ribs (Table 1, case 6).

Thus, the block of the interaction between the surface ectoderm and the somitic mesoderm always resulted in the lack of the distal rib, while the partial block of this interaction caused distal rib deficiency with a much lower incidence. On the other hand, the block of the interaction between the ectoderm and the lateral plate or the neural tube was less effective in cases 4 and 6 than in cases 2 and 3 . Since the inserts were approximately the same size, they covered a wider range of tissues other than the somitic mesoderm in cases 4, 6 than in cases 2, 3. These findings suggest that the development of the distal rib requires the interaction between the surface ectoderm and the somitic mesoderm.

\section{Pax 3 expression pattern}

Two days after the operation, the expression pattern of Pax3, characteristic in the dermomyotome, was examined by whole mount in situ hybridization. Pax3 expression in the somites was down regulated at the site where the PET film was inserted (Fig.6B; between arrows), compared to the control side (Fig. 6C), suggesting the block of somite-ectoderm interaction caused deficiency in the dermomyotome. We have described elsewhere changes of expression pattern of some genes in somites after the operation (Hirao and Aoyama, 2004).

\section{Discussion}

\section{Two developmental units for the rib: the proximal rib and the distal rib}

In this study we have shown that the proximal part of the rib develops depending on the notochord and the ventral neural tube, while development of the distal part depends on the surface ectoderm. In recent years the rib has been considered to be composed of two parts, the proximal rib and the distal rib. The former is a small part of the rib composed of the head, neck, tuberculum and a short proximal part of the body, while the distal rib makes up most of the body.

The proximal rib derives from the caudal half of somite, while the distal rib derives from both somite halves after re-segmentation, as concluded from human embryo observations (Sensenig, 1949) and transplantation experiments (Huang et al., 2000a; Aoyama \& Asamoto, 2000). The proximal and distal rib were shown to derive from the medial half and the lateral half of a somite, using either the chick-quail chimera or Dil labeling (Olivera-Martinez et al., 2000). Although the distal rib might not derive from the dermomyotome itself (Huang et al., 2000b; Evans, 2003), it appears very near or at the border between the dermomyotome and the sclerotome (Kato \& Aoyama, 1998; our unpublished data), according to our precise transplantation experiments.

Different genes are suggested to control the proximal rib and the distal rib independently. Using Danforth's short-tail, a notochord mutant mouse and undulated, a Pax-1 mutant mouse, Koseki etal. (1993) showed that Pax1 was responsible for proximal rib development. On the other hand, mutations in muscle-specific transcription factors often cause malformation in the distal rib. Indeed, the Myf5 knock out mouse was reported to lack distal ribs

TABLE 1

\section{LACK OF THE DISTAL RIB CAUSED BY BLOCKING THE SURFACE ECTODERM-SOMITIC MESODERM INTERACTION}

\begin{tabular}{lll} 
Case & $\begin{array}{l}\text { Tissues covered with PET film } \\
\text { 24 h after the operation* }\end{array}$ & $\begin{array}{l}\text { Embryos lacking the distal } \\
\text { rib/operated embryos (\%) }\end{array}$ \\
\hline 1 & somite & $3 / 3(100 \%)$ \\
2 & somite + lateral plate (partially) & $3 / 3(100 \%)$ \\
3 & somite + neural tube (partially) & $7 / 7(100 \%)$ \\
4 & somite (partially) + lateral plate (partially) & $6 / 21(29 \%)$ \\
5 & lateral plate (partially) & $0 / 14(0 \%)$ \\
6 & somite (partially) + neural tube (partially) & $4 / 19(21 \%)$ \\
\hline
\end{tabular}

${ }^{\star}$ The film pieces were approximately the same size. 
A

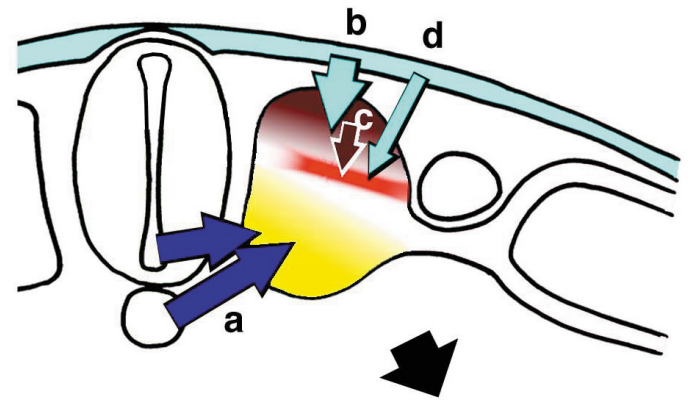

B
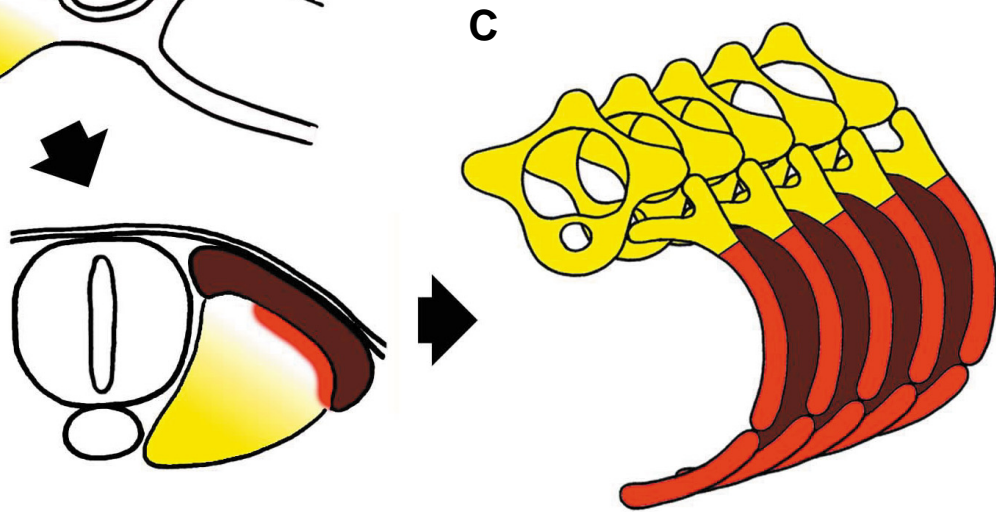

Fig. 7. The proximal rib and the distal rib development. Proximal rib development (yellow in $A B C$ ) depends on the notochord and/or the ventral part of neural tube, presumably the floor plate. Distal rib development (red in $A B C$ ) depends on the surface ectoderm. The surface ectoderm may influence the distal rib rudiment directly $(A, d)$ orindirectly through the dermomyotome $(A, b c)$. The intercostal muscles are derived from the dermomyotome that arises from the dorsal part of each somite (brown in $A B C$ ). completely (Braun et al., 1992). Whether the Myf5 gene itself is responsible for rib development was claimed to be ambiguous (Kaul et al., 2000); however, at least the development of distal rib is controlled by a gene(s), which is (are) not responsible for proximal rib development.

The proximal rib and the distal rib not only differ in their developmental origin and in genes required for their normal development, they also differ in the tissue-tissue interactions required for their development, as our present findings show.

\section{The neural tube and the notochord in the development of the proximal rib}

The axial tissues are required for the development of the axial skeleton (Teillet \& Le Douarin, 1983; Teillet et al., 1998). SHH produced by the notochord and the floor plate of neural tube mediates this interactions: Shh null mutant mice show severe defects in the axial skeleton, no rib components being formed (Chiang etal., 1996). Neural tube notochord deprivation and Shhnull knock out produce very similar phenotypes. The embryos are rescued by backtransplanting SHH-producing QT6 cells after removal of the axial tissues (Teillet et al., 1998). Thus, SHH can replace axial tissue in axial skeleton development.

While in these cases the rib is entirely missing, when we blocked the interaction between the axial tissues and the somites, only the proximal rib was affected, $\mathrm{SHH}$ being able to rescue the embryo from this deficiency. This discrepancy may be due to the different developmental stage at which somitic mesoderm was deprived of the influence of axial tissues. When we isolated the somitic mesoderm at the segmental plate stage from the axial tissues, we often found that a rib was entirely missing (Fig1D). A complete deprivation of the axial tissues in the early embryo was shown to result in somite cell death (Teillet \& Le Douarin, 1983), suggesting that the ribs were entirely eradicated when this deprivation occurred before segmentation.

On the other hand, if somitic mesoderm was deprived from axial tissue influence after segmentation began (SM-SP, SM stage), only the proximal rib was missing, similar to the Pax1 mouse mutant phenotype (Wallin et al., 1994). Pax1 has been shown responsible for formation of the ventral part of axial skeleton including the proximal rib (Wallin et al., 1994) and is expressed in the somite after segmentation (Ebensperger et al., 1995), suggesting that, among subdomains of the sclerotome (Christ et al., 2004), only the proximal rib rudiment might be affected when the operation is made after segmentation. Huang et al. (2003) showed that $\mathrm{SHH}$ indirectly regulates distal rib development through dermomyotome produced FGF8. Such influence of the axial tissues may occur before the dermomyotome differentiates, because the distal rib develops normally when axial tissues are removed after somite segmentation.

Thus, our present findings suggest that the development of the proximal rib depends on the notochord and/or the ventral neural tube, an effect which may be mediated by Shh produced by these axial tissues (Fig. 7A a).

\section{Surface ectoderm and development of the distal rib}

Ablation of the surface ectoderm has been reported to cause various types of rib malformations (Huang et al., 2000b; Sudo et al., 2001). Ribs were missing, shortened or misshapen when the surface ectoderm overlying the thoracic segmental plate was removed (Huang et al., 2000b).

Huang et al. (2000b) claimed that these rib malformations were caused by the absence of the dermomyotome, because dermomyotome development depends on the surface ectoderm (Sosic etal., 1997; Dietrich etal., 1997; Hirao and Aoyama, 2004). In fact, Huang et al. (2003) showed that the implantation of beads soaked in Fgf-8 increased rib cartilage formation, while SU 5402, an inhibitor of Fgf, caused absence of the rib cartilage near SU 5402 beads. Because Fgf- 8 is expressed in the dermomyotome (Huang et al., 2003), the lack of distal rib caused by the ablation of the surface ectoderm can be explained by a loss of the lateral part of the dermomyotome without influence of the surface ectoderm (Dietrich et al., 1997; Hirao and Aoyama, 2004).

We found that the distal rib was always missing if the somitic mesoderm was isolated from the ectoderm with a PET film at least for 24 hours. Because of the embryonic growth during these 24 hours, the film should cover not only the somitic mesoderm but also 
the neural tube and/or the lateral plate mesoderm at the time of operation. This raises a question whether the ectoderm influences somite development through the neural tube and/or the lateral plate mesoderm. However, it is unlikely that the tissues neighboring the somitic mesoderm play an important role in the interaction between the ectoderm and the somitic mesoderm. First, much fewer embryos lacked the distal rib in the cases where the somitic mesoderm was partially isolated from the ectoderm and where a broader area of the neural tube or the lateral plate was covered with film than in the cases where the somitic mesoderm was covered with film for 24 hours (Table 1). Second, in our present study, isolation of the somitic mesoderm from the neural tube caused deficiency only in the proximal rib, and the distal rib was intact when the operation was performed on the somitic mesoderm at SM-SP stage, suggesting that the distal rib can develop independently of the neural tube. Third, in the absence of the lateral plate mesoderm, the vertebral rib was not affected, while the sternal rib was missing (Sudo et al., 2001). Alternative division of the rib is the vertebral rib and the sternal rib. The distal rib itself can be divided into a vertebral part and a sternal part. Only sternal rib development depends on the lateral plate mesoderm. Thus, at least the vertebral rib part of the distal rib develops independently of the lateral plate mesoderm. Development of the lateral plate mesoderm depends on the surface ectoderm. When the surface ectoderm was ablated, the lateral plate cells died by apoptosis (Sudo et al., 2001).

Thus, the distal rib, especially its vertebral end, requires interaction between the surface ectoderm and the somitic mesoderm in its development. The surface ectoderm may control the distal rib development indirectly through regulating dermomyotome differentiation (Fig. 7A, bc), although it is also possible that the surface ectoderm influences the distal rib rudiment directly (Fig. 7A, d).

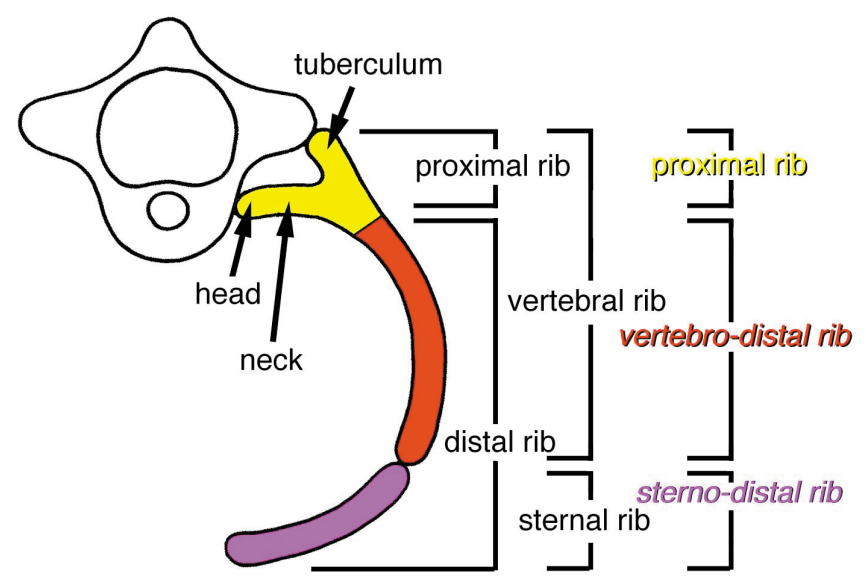

Fig. 8. Three compartments of the rib. The rib is considered to be composed of the proximal and the distal rib, or of the vertebral and the sternal rib. Combination of these two classifications makes three compartments, which are shown to develop under different controls. Proximal rib development depends on the ventral-axial tissues. Development of the vertebral rib part of the distal rib, to which we refer as vertebro-distal rib, depends on the surface ectoderm. Development of the sternal rib part of the distal rib, to which we refer as sterno-distal rib, depends on the lateral plate mesoderm. Sterno-distal rib development depends on the surface ectoderm indirectly, because differentiation and survival of lateral plate mesoderm requires surface ectoderm.
Three compartments of the rib: dependency on the ventroaxial tissues, on the surface ectoderm and on the lateral plate mesoderm

Previously, we reported that development of the sternal rib depended on the lateral plate mesoderm and the vertebral rib did not (Sudo et al., 2001). This suggests, combined with our present data, that the rib is composed of three compartments (Fig. 8), the proximal rib whose development depends on the ventral-axial tissues, the vertebral part of distal rib (vertebro-distal rib) whose development depends on the surface ectoderm and the sternal rib (sterno-distal rib ) whose development depends on the lateral plate mesoderm, which, in turn, depends on the surface ectoderm. This three compartments of ribs coincide with the three developmental origins shown by partial dermomyotome ablation (Kato and Aoyama, 1998), although the dermomyotome itself might not give rise to the rib primordium (Huang et al., 2000b).

\section{Region specific morphogenesis in the axial skeleton and diversity of the axial skeleton: primaxial / abaxial skeleton}

Considering that the rib is developmentally a complex of three compartments, the long distal rib including the sternal rib might be responsible for region specific morphogenesis of the axial skeleton units, which in turn are responsible for species-specific characteristics. The ancestors of mammals and birds might have lost the distal ribs in a region other than the thorax in the course of phylogeny.

Recently, Burke and Nowicki (2003) proposed a new classification of somite derivatives. Traditionally, trunk muscles are classified into two categories, epaxial and hypaxial muscles. Epaxial muscles, intrinsic back muscles, are characterized by their position, dorsal to the thoracolumbar fascia and by their innervations through dorsal rami of the spinal nerves (Standring, 2005). However, recent studies using mice with mutant somite derivatives have shown inconsistency between phenotypes of the mutants and epaxial/hypaxial classification. For example, in Myf5 mutant mice both epaxial (vertebral) and hypaxial (intercostal) muscles were affected (Kablar et al., 1997). Instead, Burke and Nowicki (2003) proposed new categories, primaxial and abaxial. They defined primaxial as somite cells that develop in an exclusively somitic environment and abaxial as somite cells developing into lateral plate mesoderm derivatives. They classify the vertebral ribs with their intercostal muscles as primaxial and the sternal rib with their intercostal muscles as well as abdominal muscles and limb components as abaxial.

According to primaxial/abaxial classification, it can be considered that, in mammals and birds, the primaxial vertebrodistal rib is decresased in the lumbar (abdominal) region, while the abaxial sterno-distal rib with its associated muscles might change into abdominal muscles and/or limb muscles. Thus, region specific as well as species specific morphogenesis might be considered to result from variations of each developmental compartment, primaxial/abaxial in trunk wall, proximal rib/vertebro-distal rib/ sterno-distal rib.

\section{Materials and Methods}

\section{Embryos}

Fertilized eggs of White Leghorn chick and Japanese quail were purchased from local farms and incubated in a humidified atmosphere at $38^{\circ} \mathrm{C}$. The long axis of the hen's egg was always kept in a horizontal position during incubation. 


\section{Microsurgery}

The chick embryos were operated in ovo through a window in the eggshell under a dissecting microscope. Details of general microsurgery on chick embryos in ovo were described previously (Aoyama \& Asamoto, 1988).

Insertion between the axial tissue and the somitic mesoderm: a slit was made between the neural tube and the somitic mesoderm at the thoracic level with a microscalpel made from a sewing needle. The somitic mesoderm was at a stage of segmental plate (stage SP), of segmental plate to segmented somite (stage SM-SP) or of somite (stage SM) in 2-day chick embryos. Into this slit we inserted a piece of aluminum foil with or without one of the axial tissues. These inserts are described below.

Insertion between the surface ectoderm and the somitic mesoderm: a slit was made on the surface ectoderm perpendicular to the rostro-caudal axis at the level of the segmental plate using a sharpened tungsten needle. The ectoderm was peeled away toward the thoracic level from the neural tube, the somitic mesoderm and the lateral plate mesoderm on both sides using a tungsten needle with a blunt tip. A piece of polyethylene terephthalate (PET) film was inserted into the pocket made beneath the surface ectoderm.

After the operation, the window of the eggshell was sealed with cellophane tape and the egg was further incubated at $38^{\circ} \mathrm{C}$.

\section{Inserts}

\section{Aluminum foil}

Aluminum foil for domestic use was sterilized with $70 \%$ ethanol and cut into about 1/4-1/3 X $1 \mathrm{~mm}$ pieces with a scalpel.

\section{Polyethylene terephthalate (PET) film}

Metallized polyethylene terephthalate film for capacitors of $1.8 \mu \mathrm{m}$ thickness (Oji paper company), (polyethylene terephthalate (PET) film coated with aluminum), was soaked in hydrochloric acid to remove aluminum. De-metallized PET film was rinsed with water and sterilized with $70 \%$ ethanol and cut into about $1 / 4-1 / 3 \times 1 \mathrm{~mm}$ pieces with scalpel.

Axial tissues

Two-day quail embryos around the 20 somite stage were isolated in Tyrode's solution. The part of the embryo containing the thoracic somitic mesoderm corresponding to about 6 pairs of somites was cut out and incubated in $500 \mathrm{iu} / \mathrm{ml}$ Dispase (Godo shusei Co. Ltd) in Dulbecco's modified Eagle's MEM (Nissui) supplemented with $10 \%$ fetal calf serum (Gibco) (DMEM) at room temperature for 20-60 min. The neural tube and the notochord were isolated from the surrounding tissues using sharpened tungsten needles. The neural tube was cut into left and right half and each half was cut into dorsal and ventral half, which were referred to as the dorsal neural tube and the ventral neural tube, respectively.

SHH-producing QT6 cells

A 2.5 kilo base $(\mathrm{kb})$ fragment encoding full length mouse shh cDNA (provided by Dr. A. McMahon) was subcloned into RCASBP(A) vector (Echelard et al., 1993). The retroviral vector was introduced into chicken embryonic fibroblasts by the Calcium Phosphate method and retroviral particles secreted into the culture medium (DMEM) were concentrated more than 20 times by ultracentrifugation. QT6 quail fibroblasts stably transfected with this retrovirus expressed Shh. These SHH-producing QT6 cells were grown in a monolayer in DMEM. To make an insert, we scraped the monolayer cell culture and cut into about $1 \times 1 \mathrm{~mm}$ cell sheets with a tungsten needle.

\section{Whole mount cartilaginous skeleton preparation}

Seven days after the operation (Hamburger-Hamilton stage 3537(Hamburger and Hamilton, 1951)), the embryos were fixed with Carnoy's fixative overnight and the visceral organs were removed. The embryos were stained with Alcian blue $8 \mathrm{GX}$ in $70 \%$ ethanol and $1 \% \mathrm{HCl}$ overnight (Simons and Van Horn, 1971). They were destained in $70 \%$ ethanol and $1 \%$ $\mathrm{HCl}$, dehydrated through an ethanol series and cleared in methyl salicylate.

\section{Whole mount in situ hybridization}

In situ hybridization on whole mounts was performed according to the procedure described previously (Wilkinson, 1992) with slight modifications.
Digoxigenin-11-UTP-labeled riboprobes were prepared by in vitro transcription. For whole mount in situ hybridization, embryos were fixed overnight in $4 \%$ paraformaldehyde in phosphate-buffered saline.

\section{Probes}

Pax1: a 1.5-kb full-length quail Pax1 cDNA subcloned in pBluescript IISK(+). Pax3 : a 330-base pair fragment of the chicken Pax3 cDNA subcloned in pBluescript IISK(+)(Provided by Dr. P. Gruss).

\section{Acknowledgements}

We thank Dr. A. McMahon for mouse shh CDNA and Dr. P. Gruss for Pax3 probe. This work was supported in part by Grants-in-Aid for Scientific Research from MEXT Japan and from JSPS.

\section{References}

AOYAMA, H. (1993). Developmental plasticity of the prospective dermatome and the prospective sclerotome region of an avian somite.Develop. Growth \& Differ. 35: 507-519.

AOYAMA, H. and ASAMOTO, K. (1988). Determination of somite cells: independence of cell differentiation and morphogenesis. Development 104: 15-28.

AOYAMA, H. and ASAMOTO, K. (2000). The developmental fate of rostral/caudal half of a somite for vertebra and rib formation: experimental confirmation of the resegmentation theory using chick-quail chimeras. Mech. Dev. 99: 71-82.

AOYAMA, H., DELOUVEE, A., THIERY, J.P. (1985). Cell adhesion mechanisms in gangliogenesis studied in avian embryo and in a model system. Cell Differ. 17: 247-260.

BORYCKI, A.G., MENDHAM, L. and EMERSON C.P. JR. (1997). Control of somite patterning by Sonic hedgehog and its downstream signal response genes. Development 125, 777-790.

BORYCKI, A.G. AND EMERSON, C.P. JR. (2000). Multiple tissue interactions and signal transduction pathways control somite myogenesis. In: Ordahl C.P. (ed) Somitogenesis, part 2. Academic Press, London, pp 165-224.

BRAND-SABERI, B., EBENSPERGER, C., WILTING, J., BALLING R. and CHRIST, B. (1993). The ventralizing effect of the notochord on somite differentiation in chick embryos. Anat. Embryol. 188: 239-245.

BRAUN, T., RUDNICKI, M.A., ARNOLD, H.H. and JAENISCH, R. (1992). Targeted inactivation of the muscle regulatory gene $M y f-5$ results in abnormal rib development and perinatal death. Cel/71: 1-20.

BURKE, A.C., NELSON, A.C., MORGAN, B.A. and TABIN, C. (1995). Hox genes and the evolution of vertebrate axial morphology. Dev. Biol. 121: 333-346.

BURKE, A.C. and NOWICKI, J.L. (2003). A new view of patterning domains in the vertebrate mesoderm. Dev. Cel/4:159-165.

CARROLL, S.B., GRENIER, J.K. and WEATHERBEE, S.D. (2001). From DNA to diversity. Molecular genetics and the evolution of animal design. Blackwell Publishing.

CHEVALLIER, A. (1975). Rôle du mésoderme somitique dans le développement de la cage thoracique de l'embryon d'oiseau. I. Origine du segment sternal et mécanismes de la différenciation des côtes. J. Embryol. exp. Morphol. 33: 291-311.

CHIANG, C., LITINGTUNG, Y., LEE, E., YOUNG, K.E., CORDEN, J.L., WESTPHAL, H. and BEACHY P.A. (1996). Cyclopia and defective axial patterning in mice lacking Sonic hedgehog gene function. Nature 383: 407-413.

CHRIST, B., BRAND-SABERI, B., GRIM, M. and WILTING, J. (1992). Local signaling in dermomyotomal cell type specification. Anat. Embryol. 186: 505-510.

CHRIST, B., HUANG, R. AND SCAAL, M. (2004). Formation and differentiation of the avian sclerotome. Anat. Embryol. 208: 333-350.

CHRIST, B., JACOB, H.J., JACOB,M. (1974). Experimentelle Untersuchungen zur Entwicklung der Brustwand beim Hünerembryo. Experientia 30: 1449-1451.

CHRIST, B. and ORDAHL, C.P. (1995). Early stages of chick somite development. Anat. Embryol. 191: 381-396.

CHRIST, B., SCHMIDT, C., HUANG, R., WILTING, J. and BRAND-SABERI, B. (1998). Segmentation of the vertebrate body. Anat. Embryol. 197: 1-8.

CHRIST, B. and WILTING, J. (1992). From somites to vertebral column. Ann. Anat.174: 23-32. 
DIETRICH, S. (1999). Regulation of hypaxial muscle development. Cell Tissue Res. 296: $175-182$.

DIETRICH, S., SHUBERT, F.R. and LUMSDEN, A. (1997). Control of dorsoventral pattern in the chick paraxial mesoderm. Development, 124: 3895-3908.

DOCKTER, J. (2000). Sclerotome induction and differentiation. In: Ordahl C.P. (ed) Somitogenesis, part 2. Academic Press, London, pp 77-127.

DOCKTER, J. AND ORDAHL C.P. (2000). Dorsoventral axis determination in the somite: a re-examination. Development 127: 2201-2206.

EBENSPERGER, C., WILTING, J., BRAND-SABERI, B., MIZUTANI, Y., CHRIST, B., BALLING, R. and KOSEKI, H. (1995). Pax-1, a regulator of sclerotome development, is induced by notochord and floor plate signals in avian embryos. Anat. Embryol. 191: 297-310.

ECHELARD Y, EPSTEIN DJ, ST-JACQUES B, SHEN L, MOHLER J, MCMAHON JA and MCMAHON AP. (1993). Sonic hedgehog, a member of a family of putative signaling molecules, is implicated in the regulation of CNS polarity. Cell 75: 1417-1430.

EVANS, D.J.R. (2003). Contribution of somitic cells to the avian ribs. Dev. Biol. 256: 114-126.

FAN, C.M., PORTER, J.A., CHIANG, C., CHANG, D.T., BEACHY, P.A. AND TESSIER-LAVIGNE, M. (1995). Long-range sclerotome induction by sonic hedgehog: direct role of the amino-terminal cleavage product and modulation by the cyclic AMP signaling pathway. Cel/81: 457-465.

FAN, C.M. and TESSIER-LAVIGNE, M. (1994). Patterning of mammalian somites by surface ectoderm and notochord: evidence for sclerotome induction by a hedgehog homolog. Cel/79: 1175-1186.

GALLERA, J. (1966). Mise en évidence du rôle de l'ectoblaste dans la différenciation des somites chez les oiseaux. Rev. Suisse Zool. 73:492-503.

GOldsteIN, R.S., TEILlET, M.A. AND KALCHEIM, C. (1990). The microenvironment created by grafting rostral half-somites is mitogenic for neural crest cells. Proc. Natl. Acad. Sci. USA. 87:4476-4480.

HAMBURGER, V. and HAMILTON, H.L. (1951). A series of normal stages in the development of the chick embryo. J. Morphol. 88: 49-92.

HIRAO, A. and AOYAMA, H. (2004). Somite development without influence of the surface ectoderm in the chick embryo: The compartments of a somite responsible for distal rib development. Dev. Growth Differ. 46:351-362.

HUANG, R., ZHI, Q., BRAND-SABERI, B. and CHRIST, B. (2000a). New experimental evidence for somite resegmentation. Anat. Embryol. 202: 195-200.

HUANG, R., ZHI, Q., WILTING, J. and CHRIST, B. (2000b). Sclerotomal origin of the ribs. Development 127: 527-532.

HUANG, R., STOLTE, D., KURZ, H., EHEHALT, F., CANN, G.M., STOCKDALE, F.E., PATEL, K. and CHRIST, B. (2003). Ventral axial organs regulate expression of myotomal Fgf-8 that influences rib development. Dev. Biol. 255: 30-47.

JOHNSON, R.L., LAUFER, E., RIDDLE, R.D. and TABIN, C. (1994). Ectopic expression of Sonic hedgehog alters dorsal-ventral patterning of somites. Cell 79: 1165-1173.

KABLAR, B., KARASTEL, K., YING, C., ASAKURA, A., TAPSCOTT, S.J. and RUDNICKI, M.A. (1997). MyoD and Myf-5 differentially regulate the development of limb versus trunk skeletal muscle. Development 124: 4729-4738.

KATO, N. and AOYAMA, H. (1998). Dermomyotomal origin of the ribs as revealed by extirpation and transplantation experiments in chick and quail embryos. Development 125: 3437-3443.

KAUL, A., KOSTER, M., NEUHAUS, H. AND BRAUN, T. (2000). Myf-5 revisited: loss of early myotome formation does not lead to a rib phenotype in homozygous Myf-5 mutant mice. Cel/102: 17-19.

KIENY, M., MAUGER, A. and SENGEL P. (1972). Early regionalization of somitic mesoderm as studied by the development of axial skeleton of the chick embryo. Dev Biol. 28:142-161.
KOSEKI, H., WALLIN, J., WILTING, J., MIZUTANI, Y., KISPERT, A., EBENSPERGER, C., HERRMANN, B. G., CHRIST, B. and BALLING, R. (1993). A role for Pax-1 as a mediator of notochordal signals during the dorsoventral specification of vertebrae. Development 119: 649-660.

OLIVERA-MARTINEZ, I., COLTEY, M., DHOUAILLY, D. and POURQUIE, O. (2000). Mediolateral somitic origin of ribs and dermis determined by quailchick chimeras. Development 127: 4611-4617.

PINOT, M. (1969). Etude expérimentale de la morphogenèse de la cage thoracique chez l'embryon de poulet: mécanismes et origine du matériel. J. Embryol. exp. Morph. 21: 149-164.

RICKMANN, M., FAWCETT, J.W. and KEYNES, R.J. (1985). The migration of neural crest cells and the growth of motor axons through the rostral half of the chick somite. J Embryol. exp. Morphol. 90:437-455.

ROELINK, H., PORTER, J.A., CHIANG, C., TANABE, Y., CHANG, D.T., BEACHY, P.A. and JESSELL, T.M. (1995). Floor plate and motor neuron induction by different concentrations of the amino-terminal cleavage product of sonic hedgehog autoproteolysis. Ce//81: 445-455.

SENO, T. (1961). An experimental study on the formation of the body wall in the chick. Acta Anat. 45: 60-82.

SENSENIG, E.C. (1949). The early development of the human vertebral column. Contrib. Embryol. 33: 23-40.

SIMONS, E. V. and VAN HORN, J. R. (1971). A new procedure for whole-mount alcian blue staining of the cartilaginous skeleton of chicken embryos, adapted to the clearing procedure in potassium hydroxide. Acta Morphol. Neerl. -Scand. 8: 281-292.

SOSIC, D., BRAND-SABERI, B., SCHMIDT, C., CHRIST, B. and OLSON, E.N. (1997). Regulation of paraxis expression and somite formation by ectodermand neural tube-derived signals. Dev Biol. 185: 229-243.

STANDRING, S. (2005). Gray's Anatomy: The Anatomical Basis of ClinicalPractice. $39^{\text {th }}$ edition. Edinburgh: Elsevier.

SUDO, H., TAKAHASHI, Y., TONEGAWA, A., ARASE, Y., AOYAMA, H., MIZUTANIKOSEKI, Y., MORIYA, H., WILTING, J., CHRIST, B. and KOSEKI, H. (2001). Inductive signals from the somatopleure mediated by bone morphogenetic proteins are essential for the formation of the sternal component of avian ribs. Dev. Biol. 232: 284-300.

SWALLA B.J., SOLURSH M. (1984). Epithelial enhancement of connective tissue differentiation in explanted somites. J. Embryol. exp. Morphol. 79:243-55.

TAM, P.P. and TRAINOR, P.A. (1994). Specification and segmentation of the paraxial mesoderm. Anat. Embryol. 189: 275-305.

TEILLET, M.A. and LE DOUARIN, N.M. (1983). Consequences of neural tube and notochord excision on the development of the peripheral nervous system in the chick embryo. Dev Biol. 98:192-211.

TEILLET., M.A., WATANABE, Y., JEFFS, P., DUPREZ, D., LAPOINTE, F. and LE DOUARIN, N.M. (1998). Sonic hedgehog is required for survival of both myogenic and chondrogenic somitic lineages. Development 125: 2019-2030.

WALLIN, J., WILTING, J., KOSEKI, H., FRITSCH, R., CHRIST, B. and BALLING, R. (1994). The role of Pax-1 in axial skeleton development. Development 120: 1109-1121.

WATTERSON, R., FOWLER, I. and FOWLER, B. (1954). The role of the neural tube and notochord in development of the axial skeleton of the chick. Am. J. Anat. 95: 337-399.

WILKINSON, D.G. (1992). In Situ Hybridization: A Practical Approach. Oxford University Press, Oxford.

YAMADA, T., PLACZEK, M., TANAKA, H., DODD, J. and JESSELL, T.M. (1991). Control of cell pattern in the developing nervous system: polarizing activity of the floor plate and notochord. Cel/64: 635-647. 